Joanna Filioti

Kleomenis Spiroglou

Christos P. Panteliadis

Emmanuel Roilides

\section{Invasive candidiasis in pediatric intensive care patients: epidemiology, risk factors, management, and outcome}

Published online: 16 June 2007

(C) Springer-Verlag 2007

The online version of the original can be found at http://dx.doi.org/10.1007/s00134-007-0672-5.

J. Filioti $\cdot$ K. Spiroglou $\cdot$ E. Roilides $(-)$

Aristotle University, Hippokration Hospital, 3rd Department of Pediatrics,

Konstantinoupoleos 49, 54642 Thessaloniki, Greece

e-mail: roilides@med.auth.gr

Tel.: +30-2310-892444

Fax: +30-2310-992983

C. P. Panteliadis

University of Thessaloniki, Department of Paediatrics and Paediatric Neurology,

Kosti Palama 4, 55133 Thessaloniki, Greece

e-mail: cpantel@hol.gr

\section{Intensive Care Med (2007)}

DOI 10.1007/s00134-007-0672-5

The name of one of the co-authors was omitted from the manuscript submitted for publication. The complete authorship is given here. 